Check for updates

Cite this: RSC Adv., 2017, 7, 39198

Received 8th June 2017

Accepted 5th August 2017

DOI: $10.1039 / c 7 r a 06413 f$

rsc.li/rsc-advances

\section{Structural, magnetic and electrical properties in Al-substitued NiZnCo ferrite prepared via the sol-gel auto-combustion method for LTCC technology}

\author{
Le-Zhong Li, (DD *a Xiao-Xi Zhong, ${ }^{a}$ Rui Wang, ${ }^{a}$ Xiao-Qiang Tu, ${ }^{a}$ Lei He, ${ }^{a}$ Rong-Di Guo ${ }^{b}$ \\ and Zhi-Yong $\mathrm{Xu}^{\mathrm{C}}$
}

Al-substituted NiZnCo ferrite, $\mathrm{Ni}_{0.4} \mathrm{Zn}_{0.5} \mathrm{Co}_{0.1} \mathrm{Al}_{x} \mathrm{Fe}_{2-x} \mathrm{O}_{4}(\mathrm{O} \leq x \leq 0.20)$, were synthesized by the sol-gel auto-combustion method. The effects of Al substitution on the structural, magnetic and electrical properties have been investigated. The X-ray diffraction patterns show that the lattice parameter decreases with the increase of Al substitution. The SEM images show that the grain size decreases with the increase of Al substitution. The initial magnetic permeability reaches the maximum value when $\mathrm{Al}$ substitution is 0.05 . The resonance frequency is inversely proportional to initial magnetic permeability which obeys Snoek's law. The temperature coefficient reaches the maximum value when Al substitution is 0.05 , and it has the minimum value when Al substitution is 0.20 . The Curie temperature decreases with the increase of $\mathrm{Al}$ temperature due to the number of nonmagnetic $\mathrm{Al}^{3+}$ ions increase results in the decrease of superexchange interaction. The saturation magnetization and coercivity of the ferrite decrease linearly with the increase of $\mathrm{Al}$ substitution. The real dielectric constant of $\mathrm{Ni}_{0.4} \mathrm{Zn}_{0.5} \mathrm{Co}_{0.1} \mathrm{Al}_{x} \mathrm{Fe}_{2-x} \mathrm{O}_{4}$ ferrite decreases exponentially as frequency increases, and the dielectric constants decrease with the increase of Al substitution. The direct-current resistivity decreases and follows an exponential decay with the increase of temperature, and it increases with Al substitution.

\section{Introduction}

Low-temperature co-fired ceramic (LTCC) is one of the key technologies for manufacturing multilayered ceramic structures, which has comprehensively been used in the integration of passive components into monolithic devices. There are several layers of substrate material in which are buried capacitor, inductor, resistor, resonator, and filter components in the module.

As a kind of soft magnetic ferrite, the polycrystalline NiCuZn ferrites extensively used in multilayer chip inductors (MLCI) because they exhibit excellent magnetic properties, high electrical resistivity, and good chemical stability. ${ }^{\mathbf{1 - 5}}$

To integrate ferrite materials in LTCC technology, their sintering temperatures have to be reduced to less than $950{ }^{\circ} \mathrm{C}$ to avoid $\mathrm{Ag}$ diffusion and shrinkage since the melting temperature of silver metallization is $962{ }^{\circ} \mathrm{C}$. However, sintering

${ }^{a}$ Sichuan Province Key Laboratory of Information Materials and Devices Application, College of Optoelectronic Technology, Chengdu University of Information Technology, Chengdu 610225, People's Republic of China. E-mail: lezhong_li@163. com

${ }^{b}$ State Key Laboratory of Electronic Thin Films and Integrated Devices, University of Electronic Science and Technology of China, Chengdu 610054, China

${ }^{c}$ School of Electronic Information \& Mechanical Electrical Engineering, Zhaoqing University, Zhaoqing, 526061, China temperatures of typical ferrite materials are much higher than $950^{\circ} \mathrm{C}$. Under this condition, there are main two approaches to obtain dense samples with optimized microstructures after firing below $950{ }^{\circ} \mathrm{C}$. One approach is to introduce single or multiple effective sintering additives to NiCuZn ferrite to form liquid phases in grain boundaries for promoting the densification and reducing the sintering temperature..$^{5-10}$ Another approach to obtain dense ferrite materials after firing below $950{ }^{\circ} \mathrm{C}$ is by using high sinter-active ferrite powders prepared by alternative synthesis routes. ${ }^{\mathbf{1 1 - 1 4}}$

In present work, NiZnCo ferrite nanopowders were prepared by the sol-gel auto-combustion method due to it has advantages of being able to use inexpensive precursors and a simple preparation process. Especially, the well dispersed homogenous, nano-sized and high sinter-active ferrite powder can be obtained at low sintering temperature. ${ }^{13}$ Accordingly, the effects of $\mathrm{Al}$ substitution on the structural, magnetic and electrical properties of NiZnCo ferrite after firing at $950^{\circ} \mathrm{C}$ are investigated.

\section{Experimental procedures}

\subsection{Preparation of Al-substituted NiZnCo ferrite}

The samples of $\mathrm{Ni}_{0.4} \mathrm{Zn}_{0.5} \mathrm{Co}_{0.1} \mathrm{Al}_{x} \mathrm{Fe}_{2-x} \mathrm{O}_{4}(x=0,0.05,0.10,0.15$, 0.20 ) ferrite nanopowders were synthesized by the sol-gel 
auto-combustion method. The preparation process of nanopowders had been reported in our previous work. ${ }^{15}$ And then, the dried nanopowders were granulated with $10 \%$ poly-vinyl alcohol (PVA). The powder was pressed into samples with toroidal ( $\Phi 12 \mathrm{~mm} \times \Phi 8 \mathrm{~mm} \times h 5 \mathrm{~mm}$ ) and disc shape $(\Phi 10 \mathrm{~mm}$ $\times h 5 \mathrm{~mm}$ ), which were sintered at $950{ }^{\circ} \mathrm{C}$ for $4 \mathrm{~h}$ in air to yield the final samples.

\subsection{Characterization and property measurements}

The phase identification of the prepared ferrite samples was performed by DX 2700 X-ray diffractometer (XRD) (Cu target, $\mathrm{K}_{\alpha}$ radiation, $\lambda=1.5406 \AA$ ) at room temperature. The microstructures were observed by the JEOL JSM-6490L scanning electron microscope (SEM). The frequency dependence of initial permeability of the prepared ferrite samples were measured by HP4291B impedance analyzer from $1 \mathrm{MHz}$ to $1.8 \mathrm{GHz}$. The temperature dependence of initial permeability of the prepared ferrite samples were measured by WK 6500P LCR meter bridge from room temperature to $300{ }^{\circ} \mathrm{C}$. The hysteresis loops of samples were measured at room temperature by using a TOEI VSM-5S-15 vibrating sample magnetometer (VSM). The dielectric constant $\left(\varepsilon^{\prime}\right)$ measurement were carried out using WK 6500P LCR meter bridge in the frequency range from $100 \mathrm{~Hz}$ to $10 \mathrm{MHz}$ at room temperature. The dc resistivity was measured with Keithley 6517B high resistance meter at the temperature ranging from room temperature to $230{ }^{\circ} \mathrm{C}$ using silver-paste contacts on both sides of disc samples.

\section{Results and discussion}

\subsection{Structural properties}

X-ray diffraction patterns of $\mathrm{Ni}_{0.4} \mathrm{Zn}_{0.5} \mathrm{Co}_{0.1} \mathrm{Al}_{x} \mathrm{Fe}_{2-x} \mathrm{O}_{4}$ ferrites are shown in Fig. 1. The patterns match well with the characteristic reflections of cubic spinel structure and without unidentified extra peaks within the experimental error and measurement precision. The lattice parameter $(a)$ and X-ray density $\left(d_{\mathrm{x}}\right)$ of all samples are calculated according to XRD data and the results are shown in Table 1 . The lattice parameter and X-ray density decrease from $0.8355 \mathrm{~nm}$ to $0.8310 \mathrm{~nm}$ and

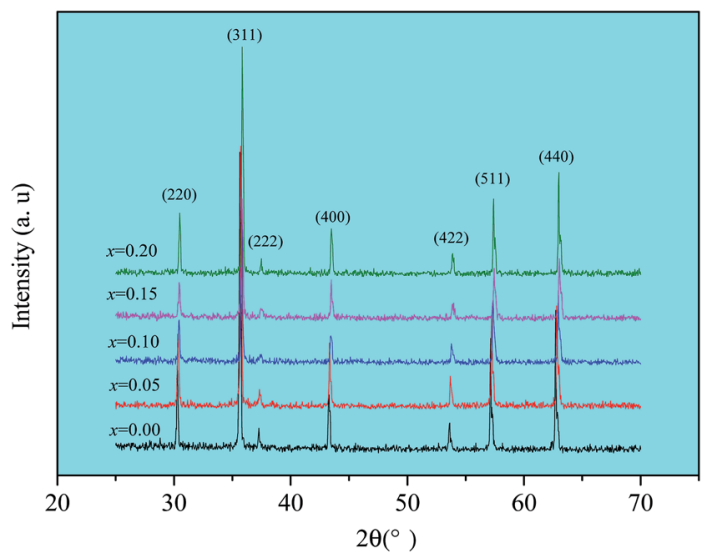

Fig. 1 X-ray diffraction patterns of $\mathrm{Ni}_{0.4} \mathrm{Zn}_{0.5} \mathrm{Co}_{0.1} \mathrm{Al}_{x} \mathrm{Fe}_{2-x} \mathrm{O}_{4}$ ferrite.
Table 1 Variations of lattice parameter (a), X-ray density $\left(d_{x}\right)$, density $(d)$ and porosity $(P)$ of $\mathrm{Ni}_{0.4} \mathrm{Zn}_{0.5} \mathrm{Co}_{0.1} \mathrm{Al}_{x} \mathrm{Fe}_{2-x} \mathrm{O}_{4}$ ferrite

\begin{tabular}{lccccc}
\hline$x$ & 0.00 & 0.05 & 0.10 & 0.15 & 0.20 \\
\hline$a(\mathrm{~nm})$ & 0.8355 & 0.8342 & 0.8325 & 0.8316 & 0.8310 \\
$d\left(\mathrm{~g} \mathrm{~cm}^{-3}\right)$ & 4.32 & 4.63 & 4.61 & 4.53 & 4.45 \\
$d_{\mathrm{x}}\left(\mathrm{g} \mathrm{cm}^{-3}\right)$ & 5.42 & 5.41 & 5.40 & 5.39 & 5.37 \\
$P(\%)$ & 20.25 & 14.42 & 14.64 & 15.92 & 17.15 \\
& & & & &
\end{tabular}

$5.42 \mathrm{~g} \mathrm{~cm}^{-3}$ to $5.37 \mathrm{~g} \mathrm{~cm}^{-3}$, respectively. The lattice parameter decrease with increasing Al substitution can be attributed to the smaller ionic radius of $\mathrm{Al}^{3+}(0.051 \mathrm{~nm})$ compared to $\mathrm{Fe}^{3+}$ ions $(0.067 \mathrm{~nm})$. As the smaller ionic radius $\mathrm{Al}^{3+}$ ions replace larger ionic radius $\mathrm{Fe}^{3+}$ ions in lattice sites, which can result in the shrinkage in the unit cell dimensions. The substitution of $\mathrm{Fe}^{3+}$ ions of higher atomic weight (55.845) with lower atomic weight $\mathrm{Al}^{3+}$ ions (26.982) results in the decrease of molecular weight from 237.8 to 232.0. Consequently, it leads to the X-ray density decrease.

Fig. 2 shows the cross section morphologies of $\mathrm{Ni}_{0.4} \mathrm{Zn}_{0.5^{-}}$ $\mathrm{Co}_{0.1} \mathrm{Al}_{x} \mathrm{Fe}_{2-x} \mathrm{O}_{4}$ ferrite. It demonstrates that the grain size decreases with the increase of Al substitution, which indicates that Al substitution inhibits the crystal growth. Similar variation in grain size with the increase of Al sustitution is also obtained in MnZn, Co, Ni, and NiZn ferrite system. ${ }^{16-20}$ It is due to small amount of aluminum oxide can be segregated at grain boundaries which inhibits the boundary movement as the second phase particle in the final sintering stage ${ }^{20}$ which can be confirmed by the EDS analysis in the grain interior and grain boundary (Fig. 3). Eventually, the grain size decreases with $\mathrm{Al}$ substitution increasing.

\subsection{Magnetic properties}

Fig. 4 illustrates the frequency and temperature dependence of the initial magnetic permeability of $\mathrm{Ni}_{0.4} \mathrm{Zn}_{0.5} \mathrm{Co}_{0.1} \mathrm{Al}_{x} \mathrm{Fe}_{2-x} \mathrm{O}_{4}$ ferrite. Fig. 4(a) indicates that the initial magnetic permeability reaches the maximum value when $\mathrm{Al}$ substitution $(x)$ is 0.05 . As shown in Table 1, the density $(d)$ have the maximum value and the porosity is the lowest when $x=0.05$ indicates that proper Al substitution can increase the density of NiZnCo ferrite, which leads to the domain wall movement and domain rotation become easier. And then, the initial magnetic permeability increases with $\mathrm{Al}$ substitution. Moreover, the magnetocrystalline anisotropy constant $\left(K_{1}\right)$ of magnetic ions is a constant except zero and the value of $K_{1}$ for nonmagnetic ions is zero, so the nonmagnetic $\mathrm{Al}^{3+}$ ions substitution can result in the decrease of $K_{1}$. And the initial permeability is inversely proportional to $K_{1}$, hence the decrease of $K_{1}$ is another reason to make the initial magnetic permeability increase. However, the decrease of initial magnetic permeability when Al substitution excess 0.05 may be due to the inhomogeneous distribution of $\mathrm{Al}^{3+}$ ions and lattice deformation with excessive $\mathrm{Al}$ substitution which can result in the increase of inner stress. In addition, Fig. 4(a) also indicates that the resonance frequency initially decreases and then increases with increasing Al substitution. In 

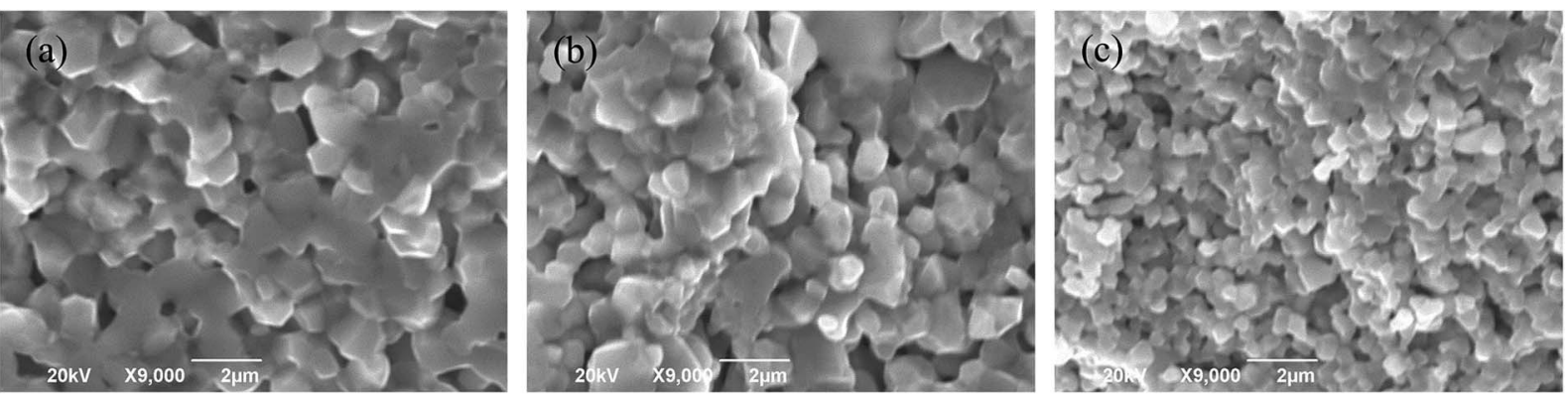

Fig. 2 SEM images of $\mathrm{Ni}_{0.4} \mathrm{Zn}_{0.5} \mathrm{Co}_{0.1} \mathrm{Al}_{x} \mathrm{Fe}_{2-x} \mathrm{O}_{4}$ ferrite.
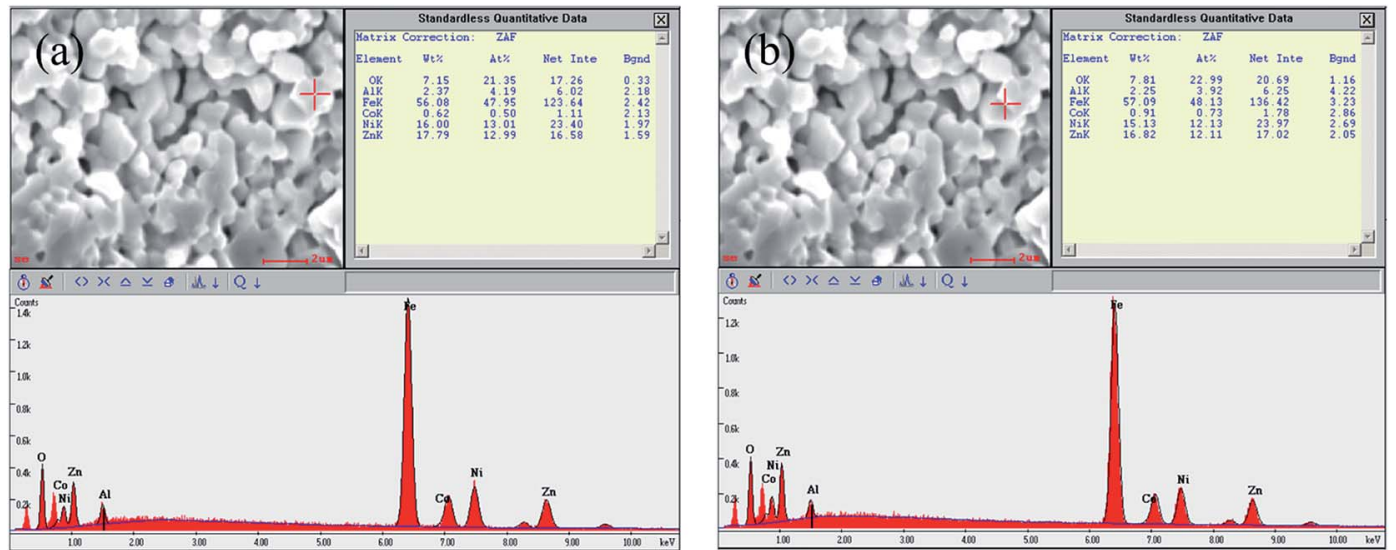

Fig. 3 EDS analysis (a) in the grain interior and (b) grain boundary of $\mathrm{Ni}_{0.4} \mathrm{Zn}_{0.5} \mathrm{Co}_{0.1} \mathrm{Al}_{0.1} \mathrm{Fe}_{1.9} \mathrm{O}_{4}$ ferrite
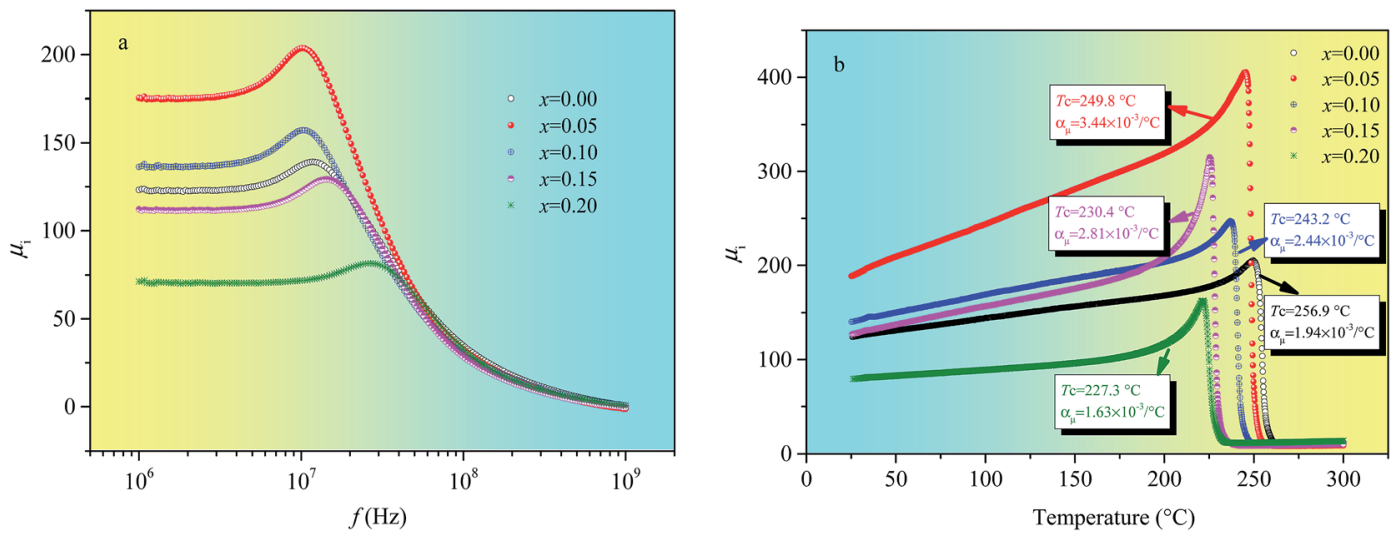

Fig. 4 Frequency (a) and temperature (b) dependence of $\mu_{\mathrm{i}}$ of $\mathrm{Ni}_{0.4} \mathrm{Zn}_{0.5} \mathrm{Co}_{0.1} \mathrm{Al}_{x} \mathrm{Fe}_{2-x} \mathrm{O}_{4}$ ferrite.

other words, the resonance frequency is inversely proportional to initial magnetic permeability which obeys the Snoek's law. ${ }^{21}$

The temperature coefficient of $\mu_{\mathrm{i}}\left(\alpha_{\mu}\right)$ among the temperature range $T_{1}$ and $T_{2}$ can be defined as $\alpha_{\mu}=\left(\mu_{2}-\mu_{1}\right) /\left(T_{2}-T_{1}\right) \mu_{1}$. Fig. 4(b) indicates that $\mathrm{Al}$ substitution has an effect on the temperature coefficients of NiZnCo ferrite. The temperature coefficient of $\mu_{\mathrm{i}}$ is obtained within the temperature range from $50{ }^{\circ} \mathrm{C}$ to $150{ }^{\circ} \mathrm{C}$ because the variation of $\mu_{\mathrm{i}}$ with temperature is linear. $\alpha_{\mu}$ reaches the maximum value $\left(3.44 \times 10^{-3}{ }^{\circ} \mathrm{C}^{-1}\right)$ with $\mathrm{Al}$ substitution is 0.05 , which mainly due to the decrease of magnetocrystalline anisotropy energy with proper $\mathrm{Al}$ substitution. And $\alpha_{\mu}$ has the minimum value $\left(1.63 \times 10^{-3}{ }^{\circ} \mathrm{C}^{-1}\right)$ when $\mathrm{Al}$ substitution is 0.20 , which properly due to the increase of inner stress because the inhomogeneous distribution of $\mathrm{Al}^{3+}$ ions and lattice deformation with excessive Al substitution. Fig. 4(b) also shows that the Curie temperature $\left(T_{\mathrm{c}}\right)$ decreases with the increase of Al temperature which mainly due to the number of magnetic ions present in the two sublattices and their superexchange interactions. The strength of the superexchange interactions depends on the angle and distance between the two 
metal cations. And among them $\mathrm{AB}$ interaction is the strongest one and $\mathrm{AA}$ interaction is the weakest one. ${ }^{22}$ Therefore, $\mathrm{AB}$ superexchange interaction becomes weaker because the magnetic $\mathrm{Fe}^{3+}$ ions are being replaced by the nonmagnetic $\mathrm{Al}^{3+}$ ions at $\mathrm{B}$ site. So, $T_{\mathrm{c}}$ decreases with the increase of $\mathrm{Al}$ substitution since it is determined by an overall strength of the A-B superexchange interaction.

Fig. 5(a) shows the hysteresis loops of $\mathrm{Ni}_{0.4} \mathrm{Zn}_{0.5} \mathrm{Co}_{0.1} \mathrm{Al}_{x^{-}}$ $\mathrm{Fe}_{2-x} \mathrm{O}_{4}$ ferrite. The saturation magnetization $\left(M_{\mathrm{S}}\right)$ and coercivity $\left(H_{\mathrm{c}}\right)$ of ferrite as a function of $\mathrm{Al}$ substitution $(x)$ are shown in Fig. 5(b). $M_{\mathrm{s}}$ and $H_{\mathrm{c}}$ decrease linearly with the increase of Al substitution.

Magnetic properties of ferrites are influenced by many factors, such as structure, composition, defects, crystallite size, internal strain and cation distribution. According to Néel's two sublattice model of ferrimagnetisms, ${ }^{22}$ the magnetic moment of cubic spinel ferrite can be calculated by $M=\left|M_{\mathrm{B}}-M_{\mathrm{A}}\right|$, where $M_{\mathrm{A}}$ and $M_{\mathrm{B}}$ are the magnetizations of A and B-sites respectively. Since the magnetic $\mathrm{Fe}^{3+}$ ions $\left(5 \mu_{\mathrm{B}}\right)$ are replaced by nonmagnetic $\mathrm{Al}^{3+}$ ions $\left(0 \mu_{\mathrm{B}}\right)$ at B-sites leads to a reduction of the magnetic ions density, which results in the decrease of the net magnetic moment at the B-sublattice $\left(M_{\mathrm{B}}\right)$ and hence the net overall magnetic moment decrease. Furthermore, the decrease of grain size and increase of internal stress due to the formation of lattice dislocation and the increase of porosity with excessive Al substitution also can make $M_{\mathrm{S}}$ decrease. Eventually, $M_{\mathrm{S}}$ decreases with the increase of $\mathrm{Al}$ substitution.

$H_{\mathrm{c}}$ as a function of $\mathrm{Al}$ substitution $(x)$ is shown in Fig. 5(b). It is observed that $H_{\mathrm{c}}$ monotonously decreases with the increase of Al substitution. On the one hand, the decrease in $H_{\mathrm{c}}$ value due to the nonmagnetic ions enter the lattices can result in the decrease of magnetocrystalline anisotropy energy. On the other hand, according to the Stoner-Wohlfarth mono-domain theory, ${ }^{23} H_{\mathrm{c}}$ increases with the increase of crystallite size when the crystallite is mono-domain structure. And the transition from mono-domain to multi-domains is supposed to occur when the grain size is around $2.9 \mu \mathrm{m} .{ }^{24}$ So, from Fig. 2, the

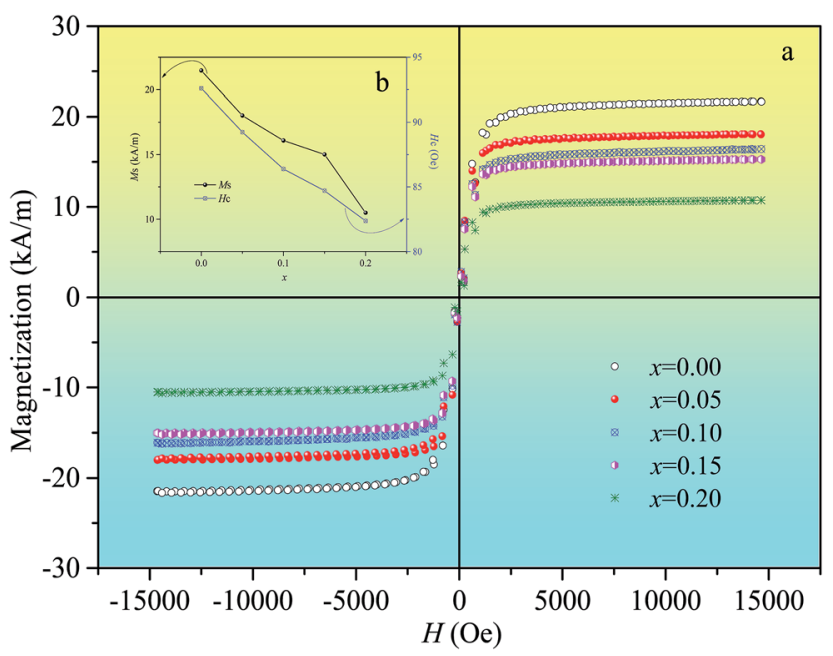

Fig. 5 Hysteresis loops (a), and variation of $M_{\mathrm{s}}$ and $H_{\mathrm{c}}$ with different substitution (b) of $\mathrm{Ni}_{0.4} \mathrm{Zn}_{0.5} \mathrm{Co}_{0.1} \mathrm{Al}_{x} \mathrm{Fe}_{2-x} \mathrm{O}_{4}$ ferrite. crystallite with mono-domain structure is another possible reason for the decrease of $H_{\mathrm{c}}$ with $\mathrm{Al}$ substitution.

\subsection{Electrical properties}

The frequency dependence of the real dielectric constant $\left(\varepsilon^{\prime}\right)$ of $\mathrm{Ni}_{0.4} \mathrm{Zn}_{0.5} \mathrm{Co}_{0.1} \mathrm{Al}_{x} \mathrm{Fe}_{2-x} \mathrm{O}_{4}$ ferrite in a frequency range from $100 \mathrm{~Hz}$ to $10 \mathrm{MHz}$ at room temperature is shown in Fig. 6. The dielectric constant is calculated using the following equation:

$$
\varepsilon^{\prime}=\frac{C \times d}{\varepsilon_{0} A}
$$

where $C$ is capacitance of the parallel plate capacitor, $d$ is the thickness of the pellet, $A$ is the cross-sectional area of the flat surface of the pellet and $\varepsilon_{0}$ is the free space dielectric constant.

Fig. 6 indicates that the real dielectric constant of $\mathrm{Ni}_{0.4} \mathrm{Zn}_{0.5^{-}}$ $\mathrm{Co}_{0.1} \mathrm{Al}_{x} \mathrm{Fe}_{2-x} \mathrm{O}_{4}$ ferrite decreases exponentially as frequency increases. The real dielectric constant decreases rapidly in low frequency region while it approaches almost frequency independent in high frequency region for all the compositions under investigation.

The dielectric polarization in ferrites is similar with the conduction hopping mechanism. Hopping between $\mathrm{Fe}^{2+}$ and $\mathrm{Fe}^{3+}$ the local displacement of electrons in the direction of the applied field occurs and these electrons determine the polarization. ${ }^{25}$ The alternating electric field causes the localized charges accumulation at grain boundaries and results in interfacial polarization. At lower frequencies, the real dielectric constant decreases rapidly due to the space charges are able to follow the frequency of the alternating field. The polarization decreases with increasing frequency and then reaches a constant value due to the fact that beyond a certain external field frequency, as a result electron exchange between $\mathrm{Fe}^{2+}$ and $\mathrm{Fe}^{3+}$ ions don't obey the variant in an alternating field. The large value of dielectric constant at lower frequency is due to the predominance of species like $\mathrm{Fe}^{2+}$ ions, interfacial dislocation piles up, oxygen vacancies, grain boundary defects, and so on. ${ }^{25}$

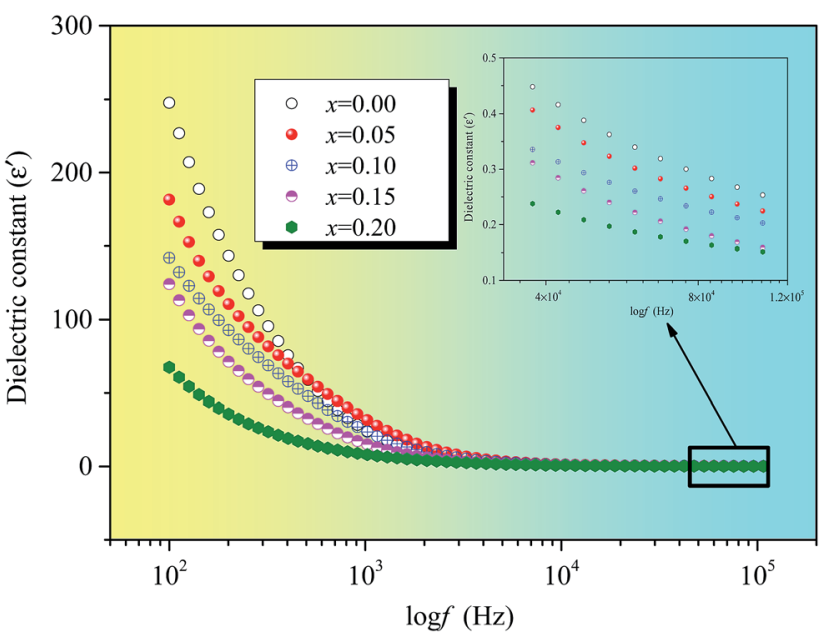

Fig. 6 Frequency dependence of $\varepsilon^{\prime}$ of $\mathrm{Ni}_{0.4} \mathrm{Zn}_{0.5} \mathrm{Co}_{0.1} \mathrm{Al}_{x} \mathrm{Fe}_{2-x} \mathrm{O}_{4}$ ferrite. 
At the same time, the decrease in the real dielectric constant with frequency because any species contributing to polarizability is found to show lagging behind the applied field at a certain higher frequencies.

Polarisation in ferrites mainly attributed to the $\mathrm{Fe}^{2+}$ ions existence because hopping between $\mathrm{Fe}^{2+}$ and $\mathrm{Fe}^{3+}$ the local displacement of electrons determine the polarization. The more $\mathrm{Fe}^{2+}$ ions, the higher dielectric constant because $\mathrm{Fe}^{2+}$ ions are easily polarizable. The insert figure of Fig. 6 clearly demonstrates that the dielectric constants decrease with the increase of Al substitution at $100 \mathrm{kHz}$. The decrease of dielectric constant can be explained on the basis of the number of available $\mathrm{Fe}^{2+}$ ions on $\mathrm{B}$ sites. And the n-type charge transfer in ferrites is due to the hopping of electrons from $\mathrm{Fe}^{2+}$ to $\mathrm{Fe}^{3+}$ ions according to $\mathrm{Fe}^{2+} \leftrightarrow \mathrm{Fe}^{3+}+\mathrm{e}^{-}$. With the increase of $\mathrm{Al}$ substitution, $\mathrm{Fe}^{2+}$ ions must be decreasing. ${ }^{26}$ Therefore, the polarization is weakened which results in the dielectric constant decrease with the increase of $\mathrm{Al}$ substitution.

Fig. 7(a) shows the temperature dependence of direct-current resistivity $\left(\rho_{\mathrm{d}}\right)$ for $\mathrm{Ni}_{0.4} \mathrm{Zn}_{0.5} \mathrm{Co}_{0.1} \mathrm{Al}_{x} \mathrm{Fe}_{2-x} \mathrm{O}_{4}(x=0-0.20)$ ferrite. It is clear that the investigated samples have semi-conducting behavior, in which $\rho_{\mathrm{d}}$ decreases and follows an exponential decay with the increase of temperature. At the same time, $\rho_{\mathrm{d}}$ increases with $\mathrm{Al}$ substitution. It is well known that the conduction mechanism for ferrites is predominantly due to hopping of electrons between $\mathrm{Fe}^{2+}$ and $\mathrm{Fe}^{3+}$ ions $\left(\mathrm{Fe}^{2+} \leftrightarrow \mathrm{Fe}^{3+}+\mathrm{e}^{-}\right) \cdot{ }^{27}$ As discussed previously, $\mathrm{Fe}^{2+}$ ions must be decreasing with the increase of $\mathrm{Al}$ substitution, which hinders the electron hopping between $\mathrm{Fe}^{3+}$ and $\mathrm{Fe}^{2+}$ ions and then it results in the increase of $\rho_{\mathrm{d}}$.

The hopping probability not only depends upon the separation between the ions involved but the activation energy. ${ }^{28}$ The relationship between direct-current resistivity and temperature obeys the well-known Arrhenius equation as $^{29}$

$$
\rho_{\mathrm{d}}=\rho_{0} \exp \left(E_{\rho} / k T\right)
$$

where $\rho_{\mathrm{d}}$ is the resistivity at temperature $T, \rho_{0}$ is the preexponential constant which equals the resistivity at infinitely

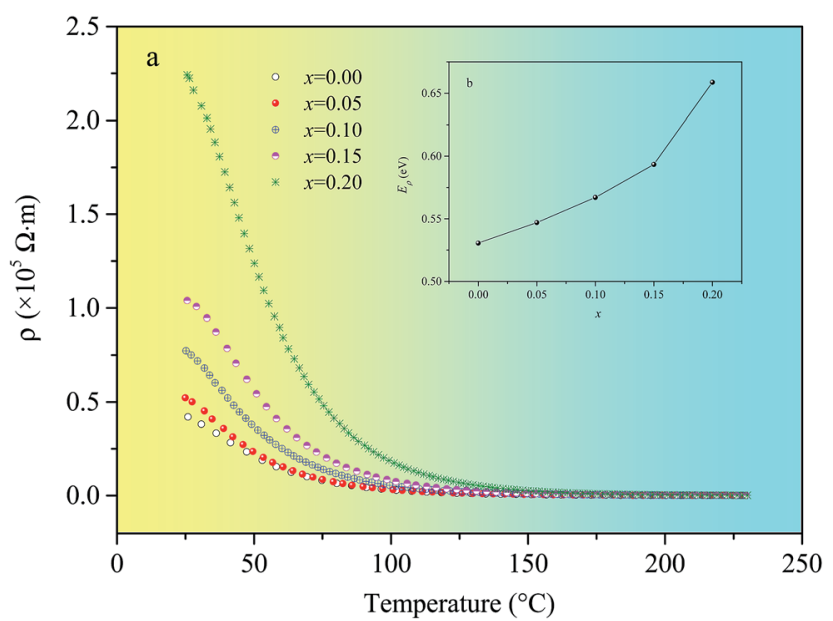

Fig. 7 Temperature dependence of $\rho_{\mathrm{d}}$ (a) and variation of $E_{\rho}$ with $x$ (b) for $\mathrm{Ni}_{0.4} \mathrm{Zn}_{0.5} \mathrm{Co}_{0.1} \mathrm{Al}_{x} \mathrm{Fe}_{2-x} \mathrm{O}_{4}$ ferrite. high temperature, $k$ is the Boltzman's constant, and $E_{\rho}$ is the activation energy. For semi-conducting behavior, from the plots of $\ln \rho$ against $1 / T$, the activation energies $E_{\rho}$ can calculated from eqn (2). ${ }^{30}$ It is noticed that the values of activation energies increased from $0.531 \mathrm{eV}(x=0)$ to $0.659 \mathrm{eV}(x=0.20)$ (Fig. 7(b)). The result indicates that the activation energy is influenced by Al substitution. The hopping depends upon the activation energy, which is associated with the electrical energy barrier experienced by the electrons during hopping. And the electronic conduction in ferrites is formed by hopping of electrons between ions of the same element present in more than one valance state, distributed randomly over crystallographically equivalent lattice sites. In other word, the electrical energy barrier becomes much higher when the $\mathrm{Fe}^{3+}$ ions are being replaced by the different element ions at the same lattice sites. So, the activation energy $E_{\rho}$ increases with increasing $\mathrm{Al}$ substitution.

\section{Conclusions}

Al-substituted NiZnCo ferrite, $\mathrm{Ni}_{0.4} \mathrm{Zn}_{0.5} \mathrm{Co}_{0.1} \mathrm{Al}_{x} \mathrm{Fe}_{2-x} \mathrm{O}_{4}(0 \leq$ $x \leq 0.20$ ), were synthesized by the sol-gel auto-combustion method. The influences of Al substitution on the structural, magnetic and electrical properties have been investigated. The lattice parameter and grain size decrease with the increase of $\mathrm{Al}$ substitution. The initial magnetic permeability reaches the maximum value when $\mathrm{Al}$ substitution is 0.05 . The resonance frequency is inversely proportional to initial magnetic permeability which obeys the Snoek's law. The temperature coefficient reaches the maximum value $\left(3.44 \times 10^{-3}{ }^{\circ} \mathrm{C}^{-1}\right)$ with $\mathrm{Al}$ substitution is 0.05 due to the decrease of magnetocrystalline anisotropy energy with proper $\mathrm{Al}$ substitution, and it has the minimum value $\left(1.63 \times 10^{-3}{ }^{\circ} \mathrm{C}^{-1}\right)$ when $\mathrm{Al}$ substitution is 0.20 because the inhomogeneous distribution of $\mathrm{Al}^{3+}$ ions and lattice deformation with excessive $\mathrm{Al}$ substitution. The Curie temperature decreases with the increase of $\mathrm{Al}$ temperature due to the number of nonmagnetic $\mathrm{Al}^{3+}$ ions increase results in the decrease of superexchange interaction. The saturation magnetization and coercivity of the ferrite decrease linearly with the increase of $\mathrm{Al}$ substitution. The real dielectric constant of $\mathrm{Ni}_{0.4} \mathrm{Zn}_{0.5} \mathrm{Co}_{0.1} \mathrm{Al}_{x} \mathrm{Fe}_{2-x} \mathrm{O}_{4}$ ferrite decreases exponentially as frequency increase, and the dielectric constants decrease with the increase of $\mathrm{Al}$ substitution. The direct-current resistivity decreases and follows an exponential decay with the increase of temperature which indicate that the investigated samples have semi-conducting behavior, and it increases with $\mathrm{Al}$ substitution.

\section{Conflicts of interest}

There are no conflicts to declare.

\section{Acknowledgements}

This work was supported by the National Natural Science Foundation of China under Grant no. 51502025. 


\section{References}

1 D. Stoppels, J. Magn. Magn. Mater., 1996, 160, 323-328.

2 H. I. Hsiang, W. C. Liao, Y. J. Wang and Y. F. Cheng, J. Eur. Ceram. Soc., 2004, 24, 2015-2021.

3 T. Krishnaveni, B. R. Kanth, V. S. R. Raju and S. R. Murthy, J. Alloys Compd., 2006, 414, 282-286.

4 P. Guzdek, J. Kulawik, K. Zaraska and A. Bieńkowski, J. Magn. Magn. Mater., 2010, 322, 2897-2901.

5 S. Zhang, L. Jia, H. Zhang, J. Li, T. Zhou and B. Liu, J. Appl. Phys., 2014, 115, 17A524.

6 X. Wang, Y. Li, J. Li, G. Yu, L. Zuo and H. Zhang, J. Mater. Sci.: Mater. Electron., 2014, 25, 4230-4234.

7 W. Ling, IEEE Trans. Magn., 2014, 50, 1-4.

8 J. C. Jao, P. Li and S. F. Wang, Jpn. J. Appl. Phys., Part 1, 2007, 46, 5792-5796.

9 X. M. Cui, J. Zhou, B. Li and Z. F. Tong, Mater. Manuf. Processes, 2007, 22, 251-255.

10 W. Ling, H. Zhang, Y. Li, D. Chen, Q. Wen and J. Shen, J. Appl. Phys., 2010, 107, 09D911.

11 Q. Yang, H. Zhang, Y. Liu, Q. Wen and L. Jia, Mater. Lett., 2012, 79, 103-105.

12 K. O. Low and F. R. Sale, J. Magn. Magn. Mater., 2003, 256, 221-226.

13 T. T. Ahmed, I. Z. Rahman and M. A. Rahman, J. Mater. Process. Technol., 2004, 153, 797-803.

14 J. Mürbe and J. Töpfer, J. Eur. Ceram. Soc., 2012, 32, 10911098.

15 L. Z. Li, Z. Yu, Z. W. Lan, K. Sun and C. J. Wu, Ceram. Int., 2014, 40, 13917-13921.
16 M. A. Gabal, A. M. Abdel-Daiem, Y. M. Angari and I. M. Ismail, Polyhedron, 2013, 57, 105-111.

17 L. Kumar and M. Kar, J. Magn. Magn. Mater., 2011, 323, 20422048.

18 B. K. Kuanr, S. R. Mishra, L. Wang, D. Conte, D. Neupane, V. Veerakumar and Z. Celinski, Mater. Res. Bull., 2016, 76, 22-27.

19 R. S. Biasi and H. F. Santos, Ceram. Int., 2017, 43, 4557-4561. 20 A. A. Birajdar, S. E. Shirsath, R. H. Kadam, M. L. Mane, D. R. Mane and A. R. Shitre, J. Appl. Phys., 2012, 112, 053908.

21 J. L. Snoek, Physica, 1948, 14, 207-217.

22 D. F. Wan and X. L. Ma, The Physics of Magnetism, UESTC Press, Chengdu, 1994.

23 E. C. Stoner and E. P. Wohlfarth, IEEE Trans. Magn., 1991, 27, 3475-3518.

24 P. J. Zagg, P. J. Valk and M. T. Rekveldt, Appl. Phys. Lett., 1996, 69, 2927-2929.

25 M. Naeem, N. A. Shah, I. H. Gul and A. Maqsood, J. Alloys Compd., 2009, 487, 739-743.

26 A. A. Sattar, H. M. El-Sayed, K. M. El-Shokrofy and M. M. El-Tabey, J. Appl. Sci., 2005, 3, 162-168.

27 E. J. W. Verwey and J. H. De Boer, Recl. Trav. Chim. Pays-Bas, 1936, 55, 531-540.

28 A. Lakshman, P. S. V. S. Rao, B. P. Rao and K. H. Rao, J. Phys. D: Appl. Phys., 2005, 38, 673-678.

29 U. V. Chhaya and R. G. Kulkarni, Mater. Lett., 1999, 39, 91-96.

30 A. Thakur, P. Mathur and M. Singh, J. Phys. Chem. Solids, 2007, 68, 378-381. 